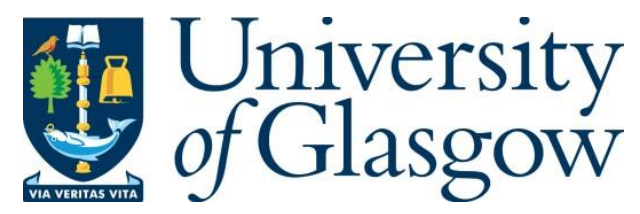

Petrie, J. R., Peters, A. L., Bergenstal, R. M., Holl, R. W., Fleming, G. A. and Heinemann, L. (2017) Improving the clinical value and utility of CGM systems: issues and recommendations: a joint statement of the European Association for the Study of Diabetes and the American Diabetes Association Diabetes Technology Working Group. Diabetes Care, 40(12), pp. 1614-1621.

There may be differences between this version and the published version. You are advised to consult the publisher's version if you wish to cite from it.

http://eprints.gla.ac.uk/151172/

Deposited on: 29 November 2017

Enlighten - Research publications by members of the University of Glasgow http://eprints.gla.ac.uk 


\title{
Improving the Clinical Value and Utility of CGM Systems: Issues and Recommendations
}

\author{
Joint Position Statement
}

\begin{abstract}
European Association for the Study of Diabetes and American Diabetes Association Diabetes Technology Working Group
\end{abstract}

\author{
John R Petrie, Anne L Peters, Richard M Bergenstal, \\ Reinhard W Holl, G Alexander Fleming, Lutz Heinemann
}

\begin{abstract}
Abbreviations: AACE - American Association of Clinical Endocrinologists; AADE American Association of Diabetes Educators; ADA - American Diabetes Association; AID Automated Insulin Delivery; AGP - Ambulatory Glucose Profile; CDER - Center for Drug Evaluation and Research; CDRH - Center for Devices and Radiologic Health; CGM Continuous Glucose Monitoring; $\mathrm{Cl}$ - Confidence Intervals; CONGA - continuous overall net glycemic action; CSII - Continuous Subcutaneous Insulin Infusion; CV - coefficient of variation; EASD - European Association for the study of Diabetes; isCGM - intermittent scanning continuous glucose monitoring; IDF - International Diabetes Federation; IQR interquartile range; ISPAD - International Society for Paediatric and Adolescent Diabetes; JDRF - Juvenile Diabetes Research Foundation; LBGI - low blood glucose index; MAGE mean amplitude of glucose excursions; MDI - Multiple Daily Injections; MODD - mean of daily difference; PRO - Patient Reported Outcomes; RCT - Randomized Controlled Trial; rtCGM - real time Continuous Glucose monitoring; SD - total standard deviation; SMBG Self Monitoring of Blood Glucose; T1D - type 1 Diabetes; T2D - type 2 Diabetes; TIR - time in range
\end{abstract}




\section{Abstract}

The first systems for continuous glucose monitoring (CGM) became available over 15 years ago. Many then believed CGM would revolutionize the use of intensive insulin therapy in diabetes; however, progress towards that vision has been gradual. Although increasing, the proportion of individuals using CGM rather than conventional systems for self-monitoring of blood glucose on a daily basis is still low in most parts of the world. Barriers to uptake include cost, measurement reliability (particularly with earlier generation systems), human factors issues, lack of a standardized format for displaying results, and uncertainty on how best to use CGM data to make therapeutic decisions. This Position Statement makes recommendations for systemic improvements in clinical usage and regulatory (pre- and postmarketing) handling of CGM devices. The aim is to improve safety and efficacy in order to support the advancement of the technology in achieving its potential to improve quality of life and health outcomes for more people with diabetes. 


\section{Introduction and Background}

Continuous glucose monitoring (CGM) is a method of continuously following glucose levels in the interstitial fluid as a basis for improving metabolic control. This includes increasing time in the target glucose range by reducing hyperglycemia and minimizing the occurrence of low glucose values (including symptomatic hypoglycemia). The international diabetes community has welcomed the introduction of CGM systems. However, daily use of these devices is associated with challenges including potential risks.

There are several ways in which CGM functions. It can either be blinded to the user or viewed in real-time. The device sends data continuously to a receiver, which allows for alerts and alarms to be provided to the wearer. Recently a form of CGM known as "flash" glucose monitoring (Freestyle Libre, Abbott) became available from one manufacturer in some countries. Although this device is based on similar technology, daily costs are lower and no calibration is required but alarms are not provided for high and low glucose values. Interstitial glucose levels are measured continuously, but as data are not transmitted continuously from the sensor, the results are available only when the sensor is scanned with a reading device. Full 24 hour data can be captured and downloaded if the sensor is scanned at least every eight hours. This latter form of CGM will be described here as intermittently-scanned continuous glucose monitoring (isCGM) (1). The glucose sensors of most CGM systems are inserted subcutaneously and worn externally by the user, although implantable CGM devices are also becoming available (2).

Following an evaluation of insulin pumps (3), the same working group of the American Diabetes Association (ADA) and the European Association for the Study of Diabetes (EASD) has now evaluated CGM and related technologies from a clinical perspective. The aim was not to replicate published position statements and overviews of CGM technology $(4,5,6)$, but instead to consider how health care professionals, CGM manufacturers, regulatory authorities, policymakers and consumers can best ensure effective and appropriate use of CGM as the technology continues to develop.

As only limited clinical trial data are required for approval of glucose monitoring devices, larger trials are often performed at a later stage with the aims of convincing payers to provide reimbursement and providing guidance on appropriate use. As such trials usually take three or more years, the marketed version of the CGM device has often been updated or modified by the time of publication. The rapidity of this development cycle means that a Position Statement can never be definitive nor comprehensive and requires regular updating.

Our goal was to assess current clinical and regulatory aspects of CGM within this rapidly-evolving landscape in order to encourage cycles of improvement in device performance, clinical outcomes, and utilization. We make a number of recommendations (marked as numbers in rectangular brackets), each targeted at relevant stakeholders 
involved in delivering safe and effective use of CGM. We gathered evidence by searching Pubmed from inception until end of November 2016 using the search terms "continuous glucose monitoring [Title/ Abstract] OR real-time glucose monitoring [Title/ Abstract] OR subcutaneous continuous glucose monitoring [Title/ Abstract] OR continuous measurement of glucose [Title/ Abstract]." We supplemented this with information from recent trial publications, abstracts, web-based resources, regulatory authorities (including from their databases), manufacturing companies and our own clinical experience.

\section{Clinical evidence}

Growing evidence supports the benefits of using CGM: the studies and clinical trials reviewed below suggest that adults with type 1 Diabetes (T1D) who wear CGM most days can improve glycemic control without increasing hypoglycemia, while those already close to target $\mathrm{HbA} 1 \mathrm{c}$ can maintain control while reducing hypoglycemia. In children and adolescents, achieving adequate adherence remains a significant barrier, although usability has improved with current generation CGM devices in this age group [2b].

a) Type 1 Diabetes (T1D): In the JDRF trial, 322 adults and children ( $\geq 8$ years of age) with $\mathrm{HbA} 1 \mathrm{c} 7.0-10.0 \%$ (53-86 mmol/mol), more than $80 \%$ using continuous subcutaneous insulin infusion (CSII), were randomized to three different CGM devices (Dexcom SEVEN (Dexcom), MiniMed Paradigm Real-Time Insulin Pump and Continous Glucose-Monitoring System (Medtronic), Freestyle Navigator (Abbott Diabetes Care)) or usual self-monitoring of blood glucose (SMBG). A significant improvement in the primary outcome of change in $\mathrm{HbA} 1 \mathrm{c}$ at 26 weeks (-0.53\%, 95\% Confidence Intervals $(\mathrm{Cl})-0.71$ to $-0.35 \%)(-5.7 \mathrm{mmol} / \mathrm{mol}, 95 \% \mathrm{Cl}$ $7.7,-3.8)$ was observed only in the subgroup defined by age $\geq 25$ years. This improvement was strongly associated with wearing the device for six or more days per week (7). In the recent DIAMOND study, in which 158 adults on multiple daily injections (MDI) were randomized (2:1) to CGM (Dexcom G4) or usual care for six months, baseline HbA1c $(8.6 \%)$ (70.5 mmol $/ \mathrm{mol})$ improved by $1.0 \%(11.0 \mathrm{mmol} / \mathrm{mol})$ with CGM and by $0.4 \%(4.3 \mathrm{mmol} / \mathrm{mol})$ with usual care (adjusted mean difference 0.6\% (6.5 mmol $/ \mathrm{mol}), \mathrm{p}<0.001)$; adherence was high (8). A further large crossover trial is in progress using the same device (9) and supportive cross-sectional real world data are available (with the various marketed devices) (10). The potential for CGM to take the place of (rather than augment) SMBG recently gained support from (REPLACE-BG), an open-label randomized trial of 226 adults with wellcontrolled T1D (HbA1c 7.1 $\pm 0.7 \%(54.0 \pm 7.6 \mathrm{mmol} / \mathrm{mol})$ at baseline) that compared "CGM only" with "CGM and SMBG": SMBG in addition to CGM had no effect on time in range (70$180 \mathrm{mg} / \mathrm{dL})(3.9-10.0 \mathrm{mmol} / \mathrm{L})$, the primary endpoint (11). For this reason, the FDA recently (December 2016) approved a specific CGM device (Dexcom G5® Mobile CGM System) to 
replace fingerstick glucose measurements in people with diabetes two years of age or older, although twice daily fingerstick calibrations remain necessary (12).

Some evidence with isCGM is also now available in T1D. In the recent IMPACT trial, 241 adults with T1D and $\mathrm{HbA} 1 \mathrm{c} \leq 7.5 \%$ (58.5 mmol $/ \mathrm{mol}$ ) (68\% treated with $\mathrm{MDI}$; $32 \%$ with CSII) wore an isCGM device for 14 days (Abbott Freestyle Libre) without access to glucose results. This period was then compared with a subsequent 14-day period when access to data was provided. The primary endpoint of time spent in hypoglycemia $(<70 \mathrm{mg} / \mathrm{dL})(<3.9$ $\mathrm{mmol} / \mathrm{L})$ was reduced by almost 90 minutes per day $(\mathrm{p}<0.0001)$ with isCGM while time in hyperglycemia $(>240 \mathrm{mg} / \mathrm{dL})(>13.3 \mathrm{mmol} / \mathrm{L})$ was also reduced by just over 20 minutes per day $(p=0.0247)$; there was no change in HbA1c over this short period (13).

b) Type 2 Diabetes (T2D): Currently there is limited evidence to support the use of CGM in this large group of individuals: further studies are required [4a, $4 b]$ : In a single center controlled trial (RCT) which randomized 100 people with T2D on a variety of therapies (excluding prandial insulin) to either SMBG or intermittent use of CGM (Dexcom SEVEN), a significant improvement in $\mathrm{HbA} 1 \mathrm{c}$ from a baseline of $8.3 \%(67.2 \mathrm{mmol} / \mathrm{mol})$ was observed over 12 weeks for CGM vs SMBG (1.0 \pm 1.1 vs $0.5 \pm 0.8 \%)(11.0 \pm 12.0$ vs $5.4 \pm 8.7 \mathrm{mmol} / \mathrm{mol})$ (14). The improvement was sustained (although attenuated) over a 40-week observational follow-up period $(0.8 \pm 1.5 \mathrm{vs} 0.2 \pm 1.3 \%)(8.7 \pm 16.3 \mathrm{vs} 2.1 \pm 14.1 \mathrm{mmol} / \mathrm{mol})(15)$. These data require replication using other $C G M$ devices and in other populations with $T 2 D$, but provide support for periodic use of CGM in those using basal insulin (16).

In the case of isCGM, a six-month trial (REPLACE, Abbott Freestyle Libre) in people with T2D on basal-bolus insulin therapy and a baseline $\mathrm{HbA} 1 \mathrm{c}$ of $8.8 \%(72.7 \mathrm{mmol} / \mathrm{L})$ showed a significant reduction in time in hypoglycemia (by almost 30 minutes), but no change in $\mathrm{HbA} 1 \mathrm{c}$, the primary endpoint (17).

The above mentioned clinical studies have undoubtedly moved the field forward, but our review of the CGM literature revealed common design limitations, including:

(i) Few studies (18) including individuals with a recent history of severe hypoglycemia [4a]

(ii) Few head-to-head comparisons (19) between CGM systems [3e, 4a],

(iii) Lack of standardization of outcome measures for glycemic control and glucose variability [1c], an issue recently highlighted at an FDA workshop (20)

(iv) Lack of consensus on appropriate patient reported outcomes (PRO) (21-23) [1d, 2e, 3c]

(v) Insufficient statistical power to detect important outcomes (i.e. insufficient study duration/ sample size) [2e, 3e]

(vi) Lack of a standard reporting format for CGM data [1c, 2a]

(vii) Insufficient guidance for participants on how best to make therapeutic decisions on the basis of CGM data [5c] 
(viii) Lack of adequate masking between active and comparator arms (with potential for a research participation or "Hawthorne" effect) (24) [4a]

\section{Meta-analyses}

A number of formal summaries of the CGM literature have been conducted (25-32). Although this suggests that the field is coming of age, review of the existing evidence base has generated diverse conclusions, ranging from "limited evidence" (Cochrane review) (26) to fully supportive (28-30). In only two of the meta-analyses have individual patient level data been combined: both of these showed a small improvement in $\mathrm{HbA1c}$ with no change in rates of hypoglycemia $(4,28)$. The others used mean values and took different approaches to inclusion and exclusion criteria, pooled data from CGM systems with different performance characteristics, and/or focused on studies financed by particular manufacturers (27). The heterogeneity of the outcome of the meta-analyses performed indicates that a more standardized and systematic approach (33) is required to avoid reaching inappropriate conclusions that could undermine the value of CGM [2f].

\section{Design and remaining limitations of CGM systems}

The design of most CGM systems has improved markedly over the years. For example, changes which are fundamental from a safety perspective have occurred at least in part because the FDA and other regulatory authorities began to require human factor studies prior to market approval (34) [1a, 3b]: these include more accurate glucose measurement, more audible alarms, and easier to read displays.

The remaining limitations can be grouped as follows:

Technical issues:

- Measurement of capillary blood glucose levels using a standard SMBG system is currently required for initial calibration and regular daily re-calibrations for all devices except isCGM.

- Episodic differences in sensor performance can be observed in the same individual (may or may not be attributable to the technology)

- Sensors are approved for use for only varying lengths of time, with implantable sensors lasting longest

User issues:

- Wearing a device continuously can be a burden

- A skin puncture is required each time for insertion of the glucose sensor into the subcutaneous skin tissue (or a small surgical procedure for an implantable device)

- $\quad$ Limited scope to personalize the user interface [2b]

Safety issues 
- Site reactions, skin rashes (to adhesives), pulling off, falling off, sweating off, losing

transmitter, receiver, issues with transmission at night, malfunctioning sensors, silencing

of alarms if smart phone is on vibrate or silent mode are frequently reported. [1a, 2g] Costs

- High costs for sensors and replacing system components

- In some settings, prohibitive amounts of paperwork to obtain approval for coverage Optimizing the technology to overcome as many of these issues as possible requires a high level of cooperation [5d] between all relevant stakeholders: regulatory agencies, manufacturing companies, academic researchers, research funding bodies, health professionals, medical associations, and patient groups (as per the specific recommendations below).

\section{Combination of CGM with insulin pumps: automated insulin delivery}

A number of different combinations of CGM systems with insulin pumps are available on the market in the EU and more recently in the US. Trends towards reductions in the occurrence of mild and severe hypoglycemic events when using such combinations have been reported $(35,36)$, but also challenged (37). These represent an intermediate step towards automated insulin delivery (AID) systems (38): rapid development has led to the recent market approval and launch of the first hybrid closed loop system (Minimed 670G (Medtronic)) (39).

Reliable CGM system performance with accurate, uninterrupted glucose information is a key component of a safe and effective performance of any such AID systems, i.e. ongoing automated adjustment of subcutaneous insulin infusion (with or without glucagon) according to ambient glucose levels. However, if there is an undetected malfunction, missing data transfer, or the algorithms do not handle the CGM data adequately, a clinically relevant adverse event can clearly ensue [3a]. As with CGM, there are likely to be rapid improvements in AID systems from one generation to the next that will challenge the pace of clinical evaluation (see above) and ask for standardized outcome measures (19-21) [1c].

\section{Glucose measurement in interstitial fluid}

The glucose sensors of CGM systems measure glucose in interstitial fluid as opposed to SMBG which measures glucose in capillary blood. Although few formal studies have been published with modern sensors, the assumption that interstitial glucose measurement results can be calibrated to capillary blood glucose accurately and reliably used as a basis for therapeutic decisions may be less warranted during periods of rapid changes in glycemia. In the post-absorptive state, there are measurable differences between capillary blood and interstitial fluid glucose. A study published in 2003 estimated that at an ambient glucose around $200 \mathrm{mg} / \mathrm{dL}$, change in interstitial glucose over time was $\cong 15 \%$ lower when glucose 
was increasing and $\cong 20 \%$ higher when glucose was decreasing [3a] (40). Such discrepancies between blood and interstitial fluid are potentially compounded by both physiological and "instrumental" time delay (i.e. while the measurement takes place) (39) and also by exercise. Adjusting the insulin dose on the basis of CGM glucose values therefore carries - at least a theoretical - risk of over- or underestimation with obvious attendant risks (41). However, despite these concerns, interstitial glucose concentrations from CGM appear sufficiently robust for successful use with $\operatorname{AID}$ systems $(38,39)$, and recent data suggest increased time in target when insulin dosing decisions are taken on the basis of CGM as opposed to SMBG (11). Time trends in glucose concentrations may be more informative than infrequent single time point estimates using SMBG, even if the latter are more accurate from an analytical point of view.

\section{Data handling and reporting}

At present, each manufacturer of CGM systems has its own format for display of glucose data. In addition, there are a number of tools in use for data display and analysis [e.g. Glooko/ Diasend (these two companies merged in 2016), Tidepool]. From a user and clinical perspective, a key aspect is how much time a given individual spent in a defined glucose range i.e. time in range (TIR). While individualized ranges may be appropriate for some individuals and situations, we believe that a standard and universal definition range for glucose TIR [e.g. 70-180 mg/dl (3.9-10.0 mmo/L)] would be desirable as an endpoint for clinical trials. However, a number of other parameters are in current use for characterization of:

(a) glucose control - mean glucose (of all readings), median glucose for all readings, area under the curve (AUC) [for 24 hours, normalized hourly, excess for 24 hours], low blood glucose index (LBGI); and

(b) glucose variability - total standard deviation (SD) [within-day or between-day], interquartile range (IQR), co-efficient of variation (CV), mean amplitude of glucose excursions (MAGE), mean of daily difference (MODD) and continuous overall net glycemic action (CONGA) and others have been described $(20,41,42)$. As stated above, reporting results from CGM trials with these diverse and non-standardized measures prevents robust comparisons between and amongst studies, hampers meta-analyses, and complicates interpretation of the evidence by payers and regulatory agencies [1d]. The Ambulatory Glucose Profile (AGP) has been recommended as a potential universal software report that could be adopted to standardize summary metrics amongst devices and manufacturers (43).

As with regular blood glucose meters, in daily practice most CGM users never actually download data from their devices (10). No systematic evaluations have been reported on the information most often used in daily life to guide insulin adjustment decisions: 
i.e. whether individuals with diabetes mostly rely for decisions on insulin dose adjustment on the current glucose value, the glucose profile over the previous few hours, or the "trend arrow" (which indicates when the blood glucose is rapidly falling or rising but differs in format between devices) $(44,45)$. [3e]

\section{Safety of CGM usage}

Scientific knowledge concerning the safety of CGM usage in daily life is limited. Many interesting user comments on safety aspects of CGM systems can be found on internet blogs, but are of limited generalizability. The manufacturers (as with insulin pumps and other medical devices) are required by the regulatory agencies to collect and report the customer complaints they receive for their product. However, the total number of CGM users is unknown as the numbers sold and operating are not currently reported (i.e. there is no denominator) and data are not reported in formats that are sufficiently consistent or easily searchable to be helpful in improving safety.

For example, on the FDA database for medical devices (MAUDE), issues attributed to user error cannot be filtered from those considered potentially device-related. A search for reports involving "Enlite" or Dexcom (as examples of specific CGM systems) showed quite different results. Problems specific to CGM systems such as skin reactions, sensor failure or hypoglycemia are not searchable terms. As the database can be searched by "event type" (death, injury, malfunction, other) and due to our focus on safety, we searched under "death" and "injury", restricting to one month each year due to the large number of monthly events listed.

From Table 2, it is clear that reporting procedures for these two device manufacturers differ substantially and change over time. Many of the reports of death could not have been related to the CGM systems as the harmed individual was not wearing the glucose sensor at the time of death, but were notified by the manufacturer as CGM supplies were no longer required. Although we found several reports of death due to hypoglycemia while wearing a CGM system, none were considered a device issue.

Our working group initiated discussions with the FDA with a view to reaching a better understanding of current safety reporting procedures. The FDA was willing to communicate directly with us but as the responsibility for reporting customer and complaints rests with individual device companies, we did not obtain any data additional to those already publicly available via MAUDE. [2c]

We also sent a set of five questions to the four CGM system manufacturing companies: Medtronic, Dexcom, Abbott and Roche. All provided complete and informative responses. The most interesting variation was in response to the question ("most common patient complaints reported through FDA's MAUDE system"): while one company provided 
specific answers, another replied that it considered this information confidential. In our view, this latter approach illustrates a fundamental impediment to improving the safety of CGM systems: if safety data reported for regulated health products are considered proprietary and are not made publicly-available, a cycle of safety improvement cannot occur. [1f, 2c]

\section{Education and training}

CGM is primarily a diagnostic technique and cannot be expected to improve glucose control per se any more than weighing scales can be expected to reduce weight. Without appropriate training, users of CGM may not be able to make optimal usage of the information provided.

Even in diabetes clinics, CGM data may not be optimally used. For example, physicians and other healthcare workers may vary in familiarity with the different approaches used in the different systems and/or data interpretation software available from each manufacturer [5b]. In addition, time and/ or financial constraints often do not permit sufficient discussion with individuals, so that the potential benefit of CGM is often not achieved.

To date, as most training programs have been developed and delivered by manufacturing companies, they focus on technical aspects of their own products rather than optimal usage of CGM as a technology to improve diabetes therapy. Training is not routinely available either to providers or users on how to react to the measurement results, either in real time or retrospectively and few programs have been systematically evaluated to determine their effectiveness. There are only a few company-independent teaching programs [SPECTRUM in Germany (46), AID Training Program in the US (47), and one website (42, 48)] supporting visualization and analysis of glucose data from SMBG, CGM and isCGM [2d, $5 b, 5 c]$. isCGM is increasingly being used without training because it can be ordered direct from the manufacturer online and be used without input from health care professionals; however, a training program is under development.

\section{Cost-benefit and reimbursement}

At present, costs of CGM are reimbursed for people with type 1 (but not type 2) diabetes $<65$ years of age by most commercial insurance companies in the US. In the US, following the FDA ruling in December 2016, Medicare Ruling 1682R in January 2017 approved coverage of "therapeutic CGM" (i.e. to replace fingerstick testing) in insulin treated individuals with type 1 and type 2 diabetes (using the Dexcom G5) (49). In Europe CGM is reimbursed in only a few countries (including Germany). $(50,51)$. This heterogeneous coverage also reflects the weaknesses and gaps in clinical evidence highlighted above. The few formal cost-benefit studies that have been published are open to interpretation and sensitive to assumptions 
made in the underlying models $(51,52)$ [1e, 3d]. Perhaps not surprisingly, CGM studies supported by manufacturers are more supportive than those performed by payers. However, some companies perform studies by providing funds and devices to an independent site that acts as a coordinating center and has independent oversight of the trial conduct and data analysis.

\section{Remote usage of CGM data: opportunities and challenges}

Having realized the potential of remotely accessed CGM for monitoring their children's glucose control when away at school or university, and frustrated that no commercial devices offering this facility had reached the market until recently (53), some parents of children with type 1 diabetes developed custom-made solutions by "hacking" commercially-available CGM products and releasing code for other users (www.nightscout.com) (54). [2g] While the underlying motivation is completely understandable and will likely stimulate larger companies to continue to innovate, such informal solutions raise safety concerns and present a challenge for the regulatory establishment as open source software is not regulated by regulatory agencies like the FDA. There are also issues of privacy and consent. [1g,2h]

The Nightscout community continues to grow on Facebook, although the first cloudbased CGM systems with remote connectivity are now commercially available. Such remote support is not reimbursed but, insofar as they are used, manufacturers increasingly have the capacity and means to interact directly with users, supporting sharing of measured glucose values with health care professionals, and learning from anonymized "big" data (55). This approach has enormous potential, but automatic downloading of CGM results on servers owned by manufacturers also carries risks and complexities in terms of liability, consent, privacy and data protection (56). Use of CGM in school settings is a new challenge to be addressed. Due to differences in legal tradition, there is higher sensitivity on these issues in Europe, particularly when data are transferred across national boundaries to largely USbased manufacturers. Guidance on cybersecurity of medical devices has recently been published (57) and the use of an international data "safe harbor" has been proposed as a solution (58). [1g, 2h]

\section{Use of CGM for therapeutic product development and regulatory purposes in clinical trials}

In clinical trials the roles of SMBG and CGM technologies substantially overlap. CGM has great potential for supporting clinical development of e.g. new insulin products and other glucose-lowering agents in people with both type 1 and type 2 diabetes. Analysis of continuously registered glucose profiles provides much more information about the impact of 
drugs on ambient glucose levels than any form of episodic SMBG (e.g. 7-point glucose profiles). For example, frequency of nocturnal or total daily hypoglycemic events as determined by CGM could be used as clinical trial endpoints [1d]: no other feasible alternative technology for accessing nocturnal hypoglycemia is available. For CGM to provide evaluable endpoints, consensus on definitions of the various levels of time in range and hypoglycemia (in clinical practice and by CGM) is urgently required amongst payers and providers $(21,43)$. On this topic there has been some very recent progress (59).

If the FDA and other regulators were to accept such consensus definitions, CGM could have significant impact on the development and refining of new diabetes treatment options. The same technology could be used for better studies of physiology and pathophysiology, e.g. understanding glucose metabolism during exercise and feeding in health and disease. A virtuous cycle could be created with increasing evidence for the value of monitoring technologies, improvement in these technologies, and demonstration of the favorable economics of wider availability. FDA's Center for Drug Evaluation and Research (CDER), which regulates drug therapies, recently examined new definitions and standards for measuring glycemia and other patient reported outcomes beyond $\mathrm{HbA1c}$ in clinical trials and expressed willingness to continue a series of meeting in an attempt to reach a consensus (21). FDA's Center for Devices and Radiologic Health (CDRH), which regulates devices and diagnostics, is supportive of the use of data from appropriately standardized CGM devices for clinical trials, as it has approved numerous trials using devices that regulate insulin delivery based on CGM values $(36,39,60)$. CDRH has generally requested that investigators utilize the key glucose outcome metrics outlined by Maahs et al. in the consensus report on artificial pancreas outcome measures for clinical trials (21).

\section{Conclusions and outlook}

Great progress has been made in CGM technology in recent years (61), but several barriers remain before it can reach its full potential either as a method for improving glycemic control in diabetes (with sufficient rigor for payers to reimburse), or as a means of assessing the efficacy of diabetes therapies (e.g. a novel insulin potentially associated with less hypoglycemia).

Insufficient evidence of clinical utility and reliability and the lack of consistent reimbursement contributes to limited use of CGM across large populations of people with diabetes who could potentially benefit. A more concerted commitment to seeking robust evidence by industry, regulators, clinical and technical experts, as well as funding and patient organizations is necessary for the necessary trials to be conducted and for the field to progress. 
CGM is a critically important technology for enabling AID systems. With further confirmation of the safety and utility of freestanding CGM technology, a more widespread uptake might be achieved.

Our recommendations can be categorized under the following themes:

- More systematic and structured pre-marketing evaluation of the performance of CGM systems [1a, 1b]

- Greater investment in trials to provide evidence of CGM value and reliability for all patient groups [4a, 4b]

- Standardization of CGM-measured glucose data reporting from clinical trials [1c]

- Improved consistency and accessibility of safety reports to regulatory authorities after market approval

- Increased communication and cooperation across stakeholder groups [2h]

We envision an ongoing role of ADA, EASD, and other professional medical associations in supporting the virtuous cycle of CGM innovation, confirmation of value to users, increased utilization, and greater resources reinvested to support innovation. For this vision to be realized without further delay, we call upon regulators and manufacturing companies to work urgently with health professionals and people with diabetes to create an environment with much greater standardization of outcome measures, a high level of attention to safety issues, and full transparency of adverse event reporting. 


\section{Recommendations:}

\section{A high level of cooperation and engagement is required amongst the following stakeholders. Specifically, we recommend:}

\section{1) Regulatory agencies should:}

a) Introduce a systematic, independent and structured pre-marketing and post approval evaluation of the performance of CGM systems including assessment of "human factors"

b) Promote the development of a consensus on which parameters should be analyzed and reported to characterize the performance of a CGM system

c) Specify a standardized CGM output format for reporting time in range and hypoglycemia for use in clinical trials

d) Review available outcomes measures (including patient-related outcomes) and specify those best used in CGM and AID studies

e) Assess available models for cost-benefit calculations and specify which should be used for CGM studies

f) Rapidly and transparently disseminate safety-related data reports on CGM to healthcare professionals

g) Protect the security and confidentiality of patient data in the era of connectivity

\section{2) Manufacturing companies should:}

a) Cooperate to standardize output formats \pm software used for analysis

b) Provide interfaces that can be personalized according to the needs of the user

c) Report all safety related data transparently to the regulatory authorities

d) Cooperate with academia and healthcare professionals on providing balanced and adequate information to people with diabetes and package the output data in standardized formats to make it easy for major electronic health record (EHR) companies to access and incorporate for clinical use.

e) Incorporate a wider range of existing outcome measures including patient-reported outcomes in study designs of adequate statistical power

f) Publish all relevant data / information collected during the clinical development of a given CGM system, e.g. the results of Human Factor studies.

g) Communicate frequently and regularly with users, user groups and families affected by diabetes in order that real needs can be identified and promptly addressed as soon as the relevant technology becomes available (e.g. remote monitoring)

h) Observe high standards of data security and patient confidentiality 


\section{3) Researchers/ academics should:}

a) Develop better algorithms to improve the performance of CGM and AID systems

b) Openly report and share the patient level results of all clinical studies

c) Develop and validate specific and appropriate patient-related outcome measures

d) Develop better models for cost-benefit analyses (in partnership with industry and regulatory bodies)

e) Work to develop and perform studies that fill genuine "gaps" in the evidence

f) Follow the recommendations made by Pickup (33) when interpreting or performing metaanalyses [including 3) b)],

g) Involve people with diabetes and their family members/caregivers in the development of CGM and AID systems for guidance and feedback.

\section{4) Research funding bodies should:}

a) Fund fewer small, underpowered studies of specific devices; instead well-designed larger "class" studies with clinically relevant endpoints using more than one CGM system and including head-to-head comparisons

b) Fund large independent registry studies.

\section{5) Patient groups, health professionals, and medical associations should:}

a) Provide and regularly update recommendations on CGM.

b) Provide minimum standards of training for providers and people with diabetes using CGM, isCGM, and AID

C) Work to develop and disseminate structured company-independent education programs e.g. SPECTRUM and standardized output of glucose metrics and glucose and insulin profiles e.g. Ambulatory Glucose Profile (AGP).

d) Work together (AACE, AADE, ADA, EASD, Endocrine Society, IDF, ISPAD, JDRF and other patient advocacy groups) to provide wider access to CGM for all people with diabetes who are willing and able to use these devices on a near daily basis

\section{6) Consumers of CGM technology_patients, family members, caregivers_should:}

a) Report device errors and malfunctions to the manufacturers and appropriate regulatory agencies

b) Provide input to the policy development processes of professional and patient advocacy associations and regulatory authorities

c) Advocate for standardization and improved accessibility of CGM safety data to facilitate product comparisons. 


\section{Acknowledgement}

The authors would like to thank Kelly Close for providing comments on this Position Statement from a consumer perspective. 


\section{References}

(1) Heinemann L, Freckmann G. CGM Versus FGM; or, Continuous Glucose Monitoring Is Not Flash Glucose Monitoring. J Diabetes Sci Technol. 2015; 9: 947-50.

(2) Kropff J, Choudhary P, Neupane S, Barnard K, Bain SC, Kapitza C, Forst T, Link M, Dehennis A, DeVries JH. Accuracy and Longevity of an Implantable Continuous Glucose Sensor in the PRECISE Study: A 180-Day, Prospective, Multicenter, Pivotal Trial. Diabetes Care. 2017 Jan;40(1):63-68.

(3) Heinemann L, Fleming GA, Petrie JR, Holl RW, Bergenstal RM, Peters AL. Insulin pump risks and benefits: a clinical appraisal of pump safety standards, adverse event reporting, and research needs: a joint statement of the European Association for the Study of Diabetes and the American Diabetes Association Diabetes Technology Working Group. Diabetes Care 2015; 38: 716-22.

(4) Bailey TS, Grunberger G, Bode BW, Handelsman Y, Hirsch IB, Jovanovič L, Roberts VL, Rodbard D, Tamborlane WV, Walsh J. American Association of Clinical Endocrinologists and American College Of Endocrinology 2016 Outpatient Glucose Monitoring Consensus Statement. Endocr Pract 2016; 22: 231-61.

(5) Klonoff DC, Buckingham B, Christiansen JS, Montori VM, Tamborlane WV, Vigersky RA, Wolpert H; Endocrine Society. Continuous glucose monitoring: an Endocrine Society Clinical Practice Guideline. J Clin Endocrinol Metab 2011; 96: 2968-79.

(6) Peters AL, Ahmann AJ, Battelino T, Evert A, Hirsch IB, Murad MH, Winter WE, Wolpert $H$. Diabetes Technology-Continuous Subcutaneous Insulin Infusion Therapy and Continuous Glucose Monitoring in Adults: An Endocrine Society Clinical Practice Guideline. J Clin Endocrinol Metab 2016; 101: 3922-3937.

(7) Juvenile Diabetes Research Foundation Continuous Glucose Monitoring Study Group, Tamborlane WV, Beck RW, Bode BW, Buckingham B, Chase HP, Clemons R, FialloScharer R, Fox LA, Gilliam LK, Hirsch IB, Huang ES, Kollman C, Kowalski AJ, Laffel L, Lawrence JM, Lee J, Mauras N, O'Grady M, Ruedy KJ, Tansey M, Tsalikian E, Weinzimer S, Wilson DM, Wolpert H, Wysocki T, Xing D. Continuous glucose monitoring and intensive treatment of type 1 diabetes. N Engl J Med 2008; 359: 146476.

(8) Beck RW, Riddlesworth T, Ruedy K, Ahmann A, Bergenstal R, Haller S, Kollman C, Kruger D, McGill JB, Polonsky W, Toschi E, Wolpert H, Price D; DIAMOND Study Group.. Effect of Continuous Glucose Monitoring on Glycemic Control in Adults With Type 1 Diabetes Using Insulin Injections: The DIAMOND Randomized Clinical Trial. JAMA 2017;317: 371-378. 
(9) Lind M, Polonsky W, Hirsch IB, Heise T, Bolinder J, Dahlqvist S, Pehrsson NG, Moström P. Design and methods of a randomized trial of continuous glucose monitoring in persons with type 1 diabetes with impaired glycemic control treated with multiple daily insulin injections (GOLD Study). J Diabetes Sci Technol 2016; 10: 754761.

(10) Wong JC, Foster NC, Maahs DM, Raghinaru D, Bergenstal RM, Ahmann AJ, Peters AL, Bode BW, Aleppo G, Hirsch IB, Kleis L, Chase HP, DuBose SN, Miller KM, Beck RW, Adi S; T1D Exchange Clinic Network. Real-time continuous glucose monitoring among participants in the T1D Exchange clinic registry. Diabetes Care 2014; 37: 27029.

(11) Aleppo G, Ruedy KJ, Riddlesworth TD, Kruger DF, Peters AL, Hirsch I, Bergenstal RM, Toschi E, Ahmann AJ, Shah VN, Rickels MR, Bode BW, Philis-Tsimikas A, Pop-Busui R, Rodriguez H, Eyth E, Bhargava A, Kollman C, Beck RW. REPLACE-BG: a randomized trial comparing continuous glucose monitoring with and without routine blood glucose monitoring in well-controlled adults with type 1 diabetes. Diabetes Care 2017; 40:538-545.

(12) See

https://www.fda.gov/NewsEvents/Newsroom/PressAnnouncements/ucm534056.htm (Accessed 21st April 2017)

(13) Bolinder J, Antuna R, Geelhoed-Duijvestijn P, Kroger J, Weitgasser R. Novel glucosesensing technology and hypoglycaemia in type 1 diabetes: a multicentre, non-masked, randomised controlled trial. Lancet 2016; 388(10057): 2254-2263.

(14) Vigersky RA, Fonda SJ, Chellappa M, Walker MS, Ehrhardt NM. Short- and long-term effects of real-time continuous glucose monitoring in patients with type 2 diabetes. Diabetes Care 2012; 35: 32-38.

(15) Ehrhardt NM, Chellappa M, Walker MS, Fonda SJ, Vigersky RA. The effect of real-time continuous glucose monitoring on glycemic control in patients with type 2 diabetes mellitus. J Diabetes Sci Technol 2011; 5: 668-675.

(16) Yoo HJ, An HG, Park SY, Ryu OH, Kim HY, Seo JA, Hong EG, Shin DH, Kim YH, Kim SG, Choi KM, Park IB, Yu JM, Baik SH. Use of a real time continuous glucose monitoring system as a motivational device for poorly controlled type 2 diabetes. Diabetes Res Clin Pract 2008; 82:73-79.

(17) Haak T, Hanaire H, Ajjan RA, Hermanns N, Riveline J, Rayman G. Flash GlucoseSensing Technology as a Replacement for Blood Glucose Monitoring for the Management of Insulin-Treated Type 2 Diabetes: a Multicenter,Open-Label Randomized Controlled Trial. Diabetes Ther 2017; 8: 55-73. 
(18) van Beers CA, DeVries JH, Kleijer SJ, Smits MM, Geelhoed-Duijvestijn PH, Kramer $\mathrm{MH}$, Diamant M, Snoek FJ, Serné EH. Continuous glucose monitoring for patients with type 1 diabetes and impaired awareness of hypoglycaemia (IN CONTROL): a randomised, open-label, crossover trial. Lancet Diabetes Endocrinol. 2016 Nov;4(11):893-902.

(19) Taleb N, Emami A, Suppere C, Messier V, Legault L, Chiasson JL, Rabasa-Lhoret R, Haidar A. Comparison of Two Continuous Glucose Monitoring Systems, Dexcom G4 Platinum and Medtronic Paradigm Veo Enlite System, at Rest and During Exercise. Diabetes Technol Ther 2016;18: 561-7.

(20) Standardizing Clinically Meaningful 1 Outcome Measures Beyond HbA1c for Type 1 Diabetes: A Consensus Statement of the American Association of Clinical Endocrinologists, the American Diabetes Association, the American Association of Diabetes Educators, the Endocrine Society, JDRF International, the Leona M. and Harry B. Helmsley Charitable Trust, the Pediatric Endocrine Society, and the T1D Exchange. Diabetes Care 2017; (in press)

(21) Maahs D. Maahs DM, Buckingham BA, Castle JR, Cinar A, Damiano ER, Dassau E, DeVries JH, Doyle FJ 3rd, Griffen SC, Haidar A, Heinemann L, Hovorka R, Jones TW, Kollman C, Kovatchev B, Levy BL, Nimri R, O'Neal DN, Philip M, Renard E, Russell SJ, Weinzimer SA, Zisser H, Lum JW. Outcome Measures for Artificial Pancreas Clinical Trials: A Consensus Report. Diabetes Care 2016; 39: 1175-9.

(22) Barnard KD, Kubiak T, Hermanns N, Heinemann L. Patient-reported outcomes and continuous glucose monitoring: can we do better with artificial pancreas devices? Diabetes Care 2015; 38: e70. doi: 10.2337/dc14-3044.

(23) Polonsky WH, Peters AL, Hessler D. The Impact of Real-Time Continuous Glucose Monitoring in Patients 65 Years and Older. J Diabetes Sci Technol 2016; 10: 892-7.

(24) McCambridge J, Witton J, Elbourne DR. Systematic review of the Hawthorne effect: new concepts are needed to study research participation effects. J Clin Epidemiol. 2014;67:267-77.

(25) Langendam M, Luijf YM, Hooft L, Devries JH, Mudde AH, Scholten RJ. Continuous glucose monitoring systems for type 1 diabetes mellitus. Cochrane Database Syst Rev 2012;1:CD008101.

(26) Gandhi GY, Kovalaske M, Kudva Y, Walsh K, Elamin MB, Beers M, Coyle C, Goalen M, Murad MS, Erwin PJ, Corpus J, Montori VM, Murad MH. Efficacy of continuous glucose monitoring in improving glycemic control and reducing hypoglycemia: a systematic review and meta-analysis of randomized trials. J Diabetes Sci Technol 2011 ; 5: 952-65. 
(27) Golicki DT, Golicka D, Groele L, Pankowska E. Continuous Glucose Monitoring System in children with type 1 diabetes mellitus: a systematic review and meta-analysis.

Diabetologia 2008;51: 233-40.

(28) Pickup JC, Freeman SC, Sutton AJ. Glycaemic control in type 1 diabetes during real time continuous glucose monitoring compared with self monitoring of blood glucose: meta-analysis of randomised controlled trials using individual patient data. BMJ 2011; 343: d3805. doi: 10.1136/bmj.d3805.

(29) Poolsup N, Suksomboon N, Kyaw AM. Systematic review and meta-analysis of the effectiveness of continuous glucose monitoring (CGM) on glucose control in diabetes. Diabetol Metab Syndr 2013; 23; 5: 39.

(30) Floyd B, Chandra P, Hall S, Phillips C, Alema-Mensah E, Strayhorn G, Ofili EO,Umpierrez GE. Comparative analysis of the efficacy of continuous glucose monitoring and self-monitoring of blood glucose in type 1 diabetes mellitus. J Diabetes Sci Technol 2012; 6:1094-1102.

(31) Golden SH, Brown T, Yeh HC, Maruthur N, Ranasinghe P, Berger Z, Suh Y, Wilson LM, Haberl EB, Bass EB. Methods for Insulin Delivery and Glucose Monitoring: Comparative Effectiveness [Internet]. Rockville (MD): Agency for Healthcare Research and Quality (US); 2012 Jul. Available from http://www.ncbi.nlm.nih.gov/books/NBK99217/PubMed PMID: 22876370.

(32) Yeh HC, Brown TT, Maruthur N, Ranasinghe P, Berger Z, Suh YD, Wilson LM, Haberl EB, Brick J, Bass EB, Golden SH. Comparative effectiveness and safety of methods of insulin delivery and glucose monitoring for diabetes mellitus: a systematic review and meta-analysis. Ann Intern Med 2012;157: 336-347.

(33) Pickup JC. The evidence base for diabetes technology: appropriate and inappropriate meta-analysis. J Diabetes Sci Technol 2013;7: 1567-74.

(34) Applying Human Factors and Usability Engineering to Medical Devices: Guidance for Industry and Food and Drug Administration Staff February 3, 2016 (draft guidance issued June 21, 2011).

http://www.fda.gov/downloads/MedicalDevices/.../UCM259760.pdf (Accessed 27th March 2017)

(35) Ly TT, Nicholas JA, Retterath A, Lim EM, Davis EA, Jones TW. Effect of sensoraugmented insulin pump therapy and automated insulin suspension vs standard insulin pump therapy on hypoglycemia in patients with type 1 diabetes: a randomized clinical trial. JAMA 2013; 310: 1240-1247.

(36) Bergenstal RM, Klonoff DC, Garg SK, Bode BW, Meredith M, Slover RH, Ahmann AJ, Welsh JB, Lee SW, Kaufman FR; ASPIRE In-Home Study Group. Threshold-based 
insulin-pump interruption for reduction of hypoglycemia. N Engl J Med 2013;369: 22432.

(37) Grunberger G, Heinemann L, Hermanns N. IQWiG Reanalyzes and Raises Questions About an Article by Ly et al Which Concluded Low Glucose Suspend Is Very Beneficial. J Diabetes Sci Technol 2015; 10: 185-90.

(38) Anderson SM, Raghinaru D, Pinsker JE, Boscari F, Renard E, Buckingham BA, Nimri R, Doyle FJ 3rd, Brown SA, Keith-Hynes P, Breton MD, Chernavvsky D, Bevier WC, Bradley PK, Bruttomesso D, Del Favero S, Calore R, Cobelli C, Avogaro A, Farret A, Place J, Ly TT, Shanmugham S, Phillip M, Dassau E, Dasanayake IS, Kollman C, Lum JW, Beck RW, Kovatchev B; Control to Range Study Group. Multinational Home Use of Closed-Loop Control Is Safe and Effective. Diabetes Care 2016; 39: 1143-1150.

(39) Bergenstal RM, Garg S, Weinzimer SA, Buckingham BA, Bode BW, Tamborlane WV, Kaufman FR. Safety of a Hybrid Closed-Loop Insulin Delivery System in Patients With Type 1 Diabetes. JAMA 2016; 316: 1407-1408.

(40) Kulcu E, Tamada JA, Reach G, Potts RO, Lesho MJ. Physiological differences between interstitial glucose and blood glucose measured in human subjects. Diabetes Care 2003;26:2405-9

(41) Siegmund T, Heinemann L, Kolassa R, Thomas A. Discrepancies Between Blood Glucose and Interstitial Glucose_-Technological Artifacts or Physiology: Implications for Selection of the Appropriate Therapeutic Target. Journal of Diabetes Science and Technology 2017; 1-7

(42) Kovatchev B, Cobelli C. Glucose Variability: Timing, Risk Analysis, and Relationship to Hypoglycemia in Diabetes. Diabetes Care 2016: 39;502-510.

(43) Bergenstal RM, Ahmann AJ, Bailey T, Beck RW, Bissen J, Buckingham B, Deeb L, Dolin RH, Garg SK, Goland R, Hirsch IB, Klonoff DC, Kruger DF, Matfin G, Mazze RS, Olson BA, Parkin C, Peters A, Powers MA, Rodriguez H, Southerland P, Strock ES, Tamborlane W, Wesley DM. Recommendations for standardizing glucose reporting and analysis to optimize clinical decision making in diabetes: the Ambulatory Glucose Profile (AGP). Diabetes Technol Ther 2013; 15: 198-211.

(44) Pettus J, Edelman SV. Use of Glucose Rate of Change Arrows to Adjust Insulin Therapy Among Individuals with Type 1 Diabetes Who Use Continuous Glucose Monitoring. Diabetes Technol Ther 2016;18 (Suppl 2): S234-242.

(45) Pettus J, Edelman SV. Differences in Use of Glucose Rate of Change (ROC) Arrows to Adjust Insulin Therapy Among Individuals With Type 1 and Type 2 Diabetes Who Use Continuous Glucose Monitoring (CGM). J Diabetes Sci Technol 2016; 10: 1087-93.

(46) Gehr B, Holder M, Kulzer B, Lange K, Liebl A, Sahm C, von Sengbusch S, Schlüter S, Siegmund T, Thurm U, Ziegler R, Freckmann G, Heinemann L for the SPECTRUM 
Group. SPECTRUM: A Training and Treatment Program for Continuous Glucose Monitoring for All Age Groups. J Diabetes Sci Technol 2017; 11: 284-289.

(47) Messer L. AID training program from a CDE perspective (in press)

(48) See: http://www.AGPreport.org (Accessed $27^{\text {th }}$ March 2017)

(49) https://med.noridianmedicare.com/web/jddme/policies/dmd-articles/coding-andcoverage-therapeutic-continuous-glucose-monitors (Accessed 18thJuly 2017)

(50) Rodbard D. Continuous Glucose Monitoring: A Review of Successes, Challenges, and Opportunities. Diabetes Technology \& Therapeutics. 2016;18(Suppl 2):S2-3-S2-13. doi:10.1089/dia.2015.0417.

(51) Heinemann L, Franc S, Phillip M, et al. Reimbursement for Continuous Glucose Monitoring: A European View. J Diabetes Sci Technol. 2012;6:1498-1502.

(52) Riemsma R, Corro Ramos I, Birnie R, Büyükkaramikli N, Armstrong N, Ryder S, Duffy S, Worthy G, AI M, Severens J, Kleijnen J. Integrated sensor-augmented pump therapy systems [the MiniMed $\circledast$ Paradigm $^{\mathrm{TM}}{ }^{\mathrm{T}}$ Veo system and the Vibe $^{\mathrm{TM}}$ and G4® PLATINUM CGM (continuous glucose monitoring) system] for managing blood glucose levels in type 1 diabetes: a systematic review and economic evaluation. Health Technol Assess. 2016 Feb;20(17):v-xxxi, 1-251.

(53) TWITTER HANDLE: \#WEARENOTWAITING

(54) Lee JM, Hirschfeld E, Wedding J. A Patient-Designed Do-It-Yourself Mobile Technology System for Diabetes: Promise and Challenges for a New Era in Medicine. JAMA 2016;315:1447-8.

(55) Nakamura K, Ebner E, Price DA. Similar estimated HbA1c results reported between patients with diabetes using CGM whether on multiple daily injections (MCI) or continuous subcutaneous insulin infusion (CSII) (abstract). Diabetes 2016; 65: (Suppl 1); $A 21$ (81-OR).

(56) Cottin VR, Gillis AM, Halligan D, Movsowitz CM. Medico-Legal Considerations of Remote Monitoring. Cardiovascular Business 2012.

http://www.cardiovascularbusiness.com/topics/healthcare-economics/protect-yourpractice-medico-legal-considerations-remote-monitoring (Accessed 27th March 2017)

(57) Klonoff DC, Kleidermacher DN. Now Is the Time for a Cybersecurity Standard for Connected Diabetes Devices. J Diabetes Sci Technol 2016; 10:623-6.

(58) See: http://europa.eu/rapid/press-release IP-16-216 en.htm (Accessed 27th March 2017)

(59) International Hypoglycaemia Study Group. Glucose concentrations of less than 3.0 $\mathrm{mmol} / \mathrm{L}(54 \mathrm{mg} / \mathrm{dL})$ should be reported in clinical trials: a joint position statement of the American Diabetes Association and the European Association for the Study of Diabetes. Diabetes Care 2017;40:155-157. 
(60) Buckingham BA, Raghinaru D, Cameron F, Bequette BW, Chase HP, Maahs DM, Slover R, Wadwa RP, Wilson DM, Ly T, Aye T, Hramiak I, Clarson C, Stein R, Gallego PH, Lum J, Sibayan J, Kollman C, Beck RW; In Home Closed Loop Study Group. Predictive Low-Glucose Insulin Suspension Reduces Duration of Nocturnal Hypoglycemia in Children Without Increasing Ketosis. Diabetes Care 2015; 38: 1197204. Erratum in: Diabetes Care; 2015; 38: 1813.

(61) Wong JC, Foster NC, Maahs DM, Raghinaru D, Bergenstal RM, Ahmann AJ, Peters AL, Bode BW, Aleppo G, Hirsch IB, Kleis L, Chase P, DuBose SN, Miller KM, Beck RW, Adi S. Real-time continuous glucose monitoring (CGM) among participants in the T1D Exchange clinic registry. Diabetes Care 2014; 37: 2702-9. 
Table 1

Search results from the MAUDE database of the FDA (number of hits)

\begin{tabular}{|l|c|c|c|c|c|c|c|c|}
\hline & Dexcom & & & & Enlite & & & \\
\hline & $\begin{array}{c}\text { Jul } \\
2013\end{array}$ & $\begin{array}{c}\text { Jul } \\
2014\end{array}$ & $\begin{array}{c}\text { Jul } \\
2015\end{array}$ & $\begin{array}{c}\text { Jul } \\
2016\end{array}$ & $\begin{array}{c}\text { Jul } \\
2013\end{array}$ & $\begin{array}{c}\text { Jul } \\
2014\end{array}$ & $\begin{array}{c}\text { Jul } \\
2015\end{array}$ & $\begin{array}{c}\text { Jul } \\
2016\end{array}$ \\
\hline All & 31 & 1979 & 3564 & 7453 & 0 & 492 & 366 & 302 \\
\hline Injury & 20 & 31 & 78 & 167 & 0 & 34 & 163 & 6 \\
\hline & & & & & & & & \\
\hline Death & 0 & 0 & 8 & 10 & 0 & 0 & 0 & 0 \\
\hline
\end{tabular}

Adverse events are not necessarily caused by the device. N.B. these data cannot be used to compare devices due different practices in reporting of adverse events (as discussed under heading "Safety of CGM usage). 